\title{
MITO E POESIA, ESPAÇOS INTERCAMBIÁVEIS
}

Luciano Dias Cavalcanti*

RESUMO: A literatura está estreitamente associada à dimensão mítica porque uma das fortes marcas da natureza literária (como a do mito) é promover o encontro do indivíduo com a memória profunda (anamnese) da cultura. A literatura - e mais especificamente a linguagem poética - quer reviver a experiência primeira da nomeação das coisas do mundo como nos primórdios. Esta experiência é essencialmente poética, inaugural situação que coloca em campos análogos o mito e a poesia.

PALAVRAS-CHAVE: Mito; Poesia; Literatura.

Os mitos nos atingem principalmente através da memória coletiva, veiculado por meio da tradição clássica e/ou arcaica dos povos primitivos ou por sua transposição para uma forma literária, o que possibilita a sua permanência, seu desenvolvimento e sua atualização. Através da literatura é possível constatar a permanência do mito, seja em suas categorias ou nas suas identidades de categorização. ${ }^{1}$ Dessa maneira, há no mito um caráter especificadamente estético, no sentido de que a mitologia pode ser vista como a matéria da

\footnotetext{
* Realizou estágio de pós-doutorado no Departamento de Literatura Brasileira da UNESP/Araraquara (20112013). Doutor em Teoria e História Literária pela Universidade Estadual de Campinas (2007), Mestre em Letras: Teoria da Literatura pela Universidade Federal de Minas Gerais (2001) e Graduado em Letras: Língua Portuguesa e suas respectivas literaturas pela Universidade Federal de Ouro Preto (1998). Tem experiência na área de Letras, com ênfase em Literatura Brasileira, Literatura Comparada e Teoria Literária, atuando principalmente nos estudos de poesia moderna e contemporânea, tendo como principais objetos de estudos os poetas Jorge de Lima, Manuel Bandeira, Carlos Drummond de Andrade e a relação entre Música Popular Brasileira e a Poesia.

${ }^{1}$ No entanto, como afirma Jabouille, “a versão literária de um mito não é o mito - o mito é a estrutura profunda e universal que sustenta a narrativa -, a análise das materializações é importante não só para conhecer os hipotéticos 'universais' psicológicos como para compreender, de uma forma integradora, os elementos caracterizantes de cada momento e de cada lugar da história, que se reflete, naturalmente, nas obras literárias contemporâneas." (JABOUILLE, 1993, p.21).
} 
qual se originou tudo, o "elemento primário", terreno e modelo para a literatura. O retorno da mitologia na literatura moderna, por exemplo, aponta para captação do essencial do drama humano através do mitológico, seja ele utilizado como tema, motivo de enriquecimento estético, meio de materialização referencial, elemento criativo e divulgador, como também por sua universalidade, atemporalidade, etc. Além desses pressupostos, podemos dizer que quando um poeta recorre ao mito em seus textos está, na verdade, em busca de um elemento intemporal e exemplar para o drama do homem no seu tempo.

Mircea Eliade chama a atenção para o fato de que o termo mito recebeu historicamente interpretações variadas. Os eruditos do século XIX o consideravam "fábula”, “invenção" e "ficção"; os modernos, ao contrário e em acordo com as sociedades arcaicas, o consideram uma "história verdadeira", que transporta consigo um caráter sagrado e exemplar. O mito carrega uma multiplicidade de significados, tornando bastante difícil o encontro de uma definição única que abarque sua complexidade significativa. Nesse sentido, Eliade apresenta uma definição que, para ele, parece menos imperfeita e mais ampla.

O mito conta uma história sagrada; ele relata um acontecimento ocorrido no tempo primordial, o tempo fabuloso do "princípio". Em outros tempos, o mito narra como, graças às façanhas dos Entes Sobrenaturais, uma realidade a existir, seja uma realidade total, o Cosmo, ou apenas um fragmento: uma ilha, uma espécie vegetal, um comportamento humano, uma instituição. É sempre, portanto, a narrativa de uma "criação": ele relata de que modo algo foi produzido e começou a ser. $\mathrm{O}$ mito fala apenas do que realmente ocorreu, do que se manifestou plenamente. Os personagens dos mitos são os Entes Sobrenaturais. Eles são conhecidos sobretudo pelo que fizeram no tempo prestigioso dos "primórdios". Os mitos revelam, portanto, sua atividade criadora e desvendam a sacralidade (ou simplesmente a "sobrenaturalidade") de suas obras (ELIADE, 1998, p.11, grifos do autor).

Pelo caráter simbólico que carrega, o mito pode ser considerado manifestação artística e geradora de arte. Em todas as civilizações, os mitos são fontes de inspiração para os mais diversos tipos de expressões artísticas, assim como as fantasias e criações imaginárias dos sonhos são também estímulos à atividade artística. Ao se relacionar com o mito a 
literatura tende a explicar, a clarificar e desenvolver o mito que havia nascido de forma fragmentária e, por vezes, pouco coerente. Desse modo, o mito se dilui de suas características originais para transformar-se em vários gêneros literários, tornando-se lenda, saga, fábula, conto, etc.: “O sermos mythicus, enquanto linguagem simbólica, permite [...] dizer mais facilmente as coisas que são difíceis de exprimir. Ou dizê-las de outra maneira." (JABOUILLI, 1993, p.44). Logo, a literatura está estreitamente associada à dimensão mítica porque uma das fortes marcas da natureza literária (como a do mito) é promover o encontro do indivíduo com a memória profunda (anamnese) da cultura. Esse encontro permite ao homem pensar sua vivência individual e coletiva e questionar tanto o seu próprio destino como o da humanidade.

É também significativo o modo semelhante em que tanto o mito quanto a literatura vão conceber o tempo e o espaço. O tempo mítico consiste na competência de resgatar o passado, revocá-lo. O mito, através das formas culturais, especialmente a artístico-literária, expressa o desejo humano de suplantar o tempo e o espaço que, nesse caso, se revela tanto nas formas culturais “primitivas” como nas modernas e atuais. No espaço mítico, a literatura pode chegar a lugares impossíveis, podendo se configurar por um modelo simbólico que nos remete a um lugar ancestral da cultura.

Outra importante característica do mito que podemos relacionar à literatura diz respeito à transformação do caos em cosmos, que pode ser considerada a própria essência do mito. De acordo com Mielietinsky, a principal destinação da mitologia é explicar o lugar do homem no mundo de modo que se procure encontrar o equilíbrio na desordem vivenciada por ele.

A mitologia transmite constantemente o menos inteligível através do mais inteligível, o não apreensível à mente através do apreensível à mente, e sobretudo o mais dificilmente resolvível através do menos dificilmente resolvível (donde as mediações). A mitologia não só não se reduz à satisfação da curiosidade do homem primitivo, como a sua ênfase cognitiva está subordinada a uma orientação harmonizadora e ordenadora definida, voltada para um enfoque integral do mundo no qual não se admitem os mínimos elementos do 
caótico, da desordem. A transformação do caos em cosmos constitui o sentido fundamental da mitologia, e o caos compreende desde o início um aspecto axiológico ético (MIELIETINSKY, 1987, p.196).

Para Mielietinsky, no século XX, ocorre o fenômeno da "mitologização" da literatura quer como "fenômeno artístico", quer como "visão de mundo" diretamente relacionado ao seu tempo presente, de revoluções, guerras e massacres que mudaram substancialmente a História da humanidade abalando toda uma estrutura social. É devido a este "caos" que a literatura busca o "cosmos" revitalizador da ordem. Para isso, a literatura necessitou superar limites "histórico-sociais" e "espaços-temporais", acarretando-lhe um redimensionamento do tempo e do espaço, anteriormente presos à verossimilhança da representação do real. Nesse momento, a literatura, através do mito, utilizou-se da fantasia e do simbólico para ajustar sua linguagem ao tempo presente.

Ernest Cassirer aponta para o alto poder da palavra no universo mítico das cosmogonias, chegando mesmo a ser comparada ao poder dos deuses, ou mesmo, maior que eles. Ao analisar a relação entre linguagem e mito, o teórico assinala a possível origem comum da consciência mítica e da consciência linguística no sentido de que ambas as linguagens assentam-se na mesma concepção mental: o pensamento metafórico.

A linguagem e o mito se acham originalmente em correlação indissolúvel, da qual só aos poucos cada um se vai despendendo como membro independente. Ambos são ramos diversos da mesma enformação simbólica, que brota de um mesmo ato fundamental, e da elaboração espiritual, da concentração e elevação da simples percepção sensorial. Nos fonemas da linguagem, assim como nas primitivas configurações míticas, consuma-se o mesmo processo interior; ambos constituem a resolução de uma tensão interna, a representação de moções e comoções anímicas em determinadas formações e conformações objetivas. (CASSIRER, 1985, p.106)

Desse modo, como as metáforas, o mito exerce a função de fazer falar os níveis mais profundos do ser humano. Por meio da expressão simbólica o homem pode vislumbrar seus questionamentos mais íntimos, que também são universais. 
Este mecanismo de fazer falar o incognoscível (desejo do homem de todos os tempos) se realiza plenamente na criação artística. Mas, o mais importante para expressão literária não é a ideia de que os mitos são metáforas do comportamento humano, mas o modo como a linguagem será trabalhada pelo escritor por meio da elaboração de metáforas e imagens que busquem o conhecimento original na tentativa de expressar em "verbo" um tipo de conhecimento oculto aos homens. É também devido a este desejo, intrínseco ao homem, que uma grande parte da literatura moderna procurou recuperar a visão mítica na criação artística, utilizando-a como uma espécie de suporte para adentrar nas zonas mais conflitantes e obscuras do homem de seu tempo. Em um mundo caracteristicamente fragmentado e complexo, os artistas aspiram, por meio da visão mítica, à reconquista da unidade perdida.

Nesse sentido, a literatura - e mais especificamente a linguagem poética - não se limitará apenas a um papel comunicativo. Ela supera esse caráter pragmático, utilitário, que deseja contar algo. Ela quer reviver a experiência primeira da nomeação das coisas do mundo como nos primórdios. Esta experiência é essencialmente poética, inaugural e anunciadora de um novo mundo extraordinário que contém uma "plenitude inacessível”. Este narrar inaugural é poiesis, fundação de um novo mundo: "A palavra originária significa fazer eclodir algo, trazer algo ao ser num salto fundador, a partir da proveniência da essência." (HEIDEGGER, 2010, p.199). Para Heidegger, em um sentido essencial, a própria linguagem é poiesis.

Mas porque a linguagem é aquele acontecimento no qual, a cada vez, o sendo como sendo se abre pela primeira vez para o ser humano, por isso é a poesia, a poiesis em sentido mais restrito, a mais originária poiesis em sentido essencial. A linguagem não é por isso poiesis, ou seja, porque é a poesia primordial, mas a poesia apropria-se na linguagem, porque esta conserva a essência originária da poiesis. (HEIDEGGER, 2010, p.189)

Segundo o filósofo, inversamente do que se poderia pensar, a linguagem possui o homem e não o contrário. E este só se realiza enquanto tal pela linguagem, pois "a lingua- 
gem é a morada do ser". No entanto, o homem, no cotidiano, inverte essa relação, utilizando a linguagem em vez de deixar-se manifestar por ela. Assim, o sentido original da palavra é ocultado e sua poesia desaparece. Para Heidegger, só a linguagem poética é capaz de desautomatizar a palavra de seu uso banal e fazer reaparecer sua originalidade. A partir disso, podemos dizer que a linguagem poética e/ou original (como concebida por Heidegger) assemelha-se ao mito, concebido como origem, pois o mito também funda/cria um mundo como qualquer obra de arte.

Ao se tratar da linguagem primordial não podemos deixar de mencionar o Gênesis bíblico, não como verdade revelada, mas como um campo simbólico da civilização ocidental e na sua relação com a linguagem criadora. O texto bíblico nos apresenta a linguagem como veículo místico que propicia a criação por meio do verbo. Nele está registrado o primeiro momento da criação, relacionado diretamente com a linguagem e o aparecimento do homem no mundo. Como observa Frye, a "palavra" bíblica, "inclusive o logos do Evangelho de João, estão solidamente enraizados na fase metafórica da linguagem, quando a palavra era um elemento do poder criativo. Segundo o Gênesis, 1:4, 'Deus disse, faça-se a luz; e a luz se fez'. Ou seja, a palavra foi agente da criação que levou a coisa a ser.” (FRYE, 2004, p.42). É sugestiva a semelhança da palavra bíblica com a linguagem mitológica dos primórdios. Do mesmo modo, a poesia que deseja resgatar este mundo original se utilizará da metáfora como meio de criação do poético. Nesse sentido, poderíamos dizer que a literatura é descendente direta da mitologia, visto que a poesia, assim como o mito, "recria algo que, na sociedade, é primitivo e arcaico" (FRYE, 2004, p.64). Como aponta Benjamin,

o ritmo da criação da natureza (conforme o Gênesis, 1) é: "Haja..._ Ele fez (criou) _ Ele chamou", no início e no fim dos atos, aparece, a cada vez, a profunda e clara relação do ato criador com a linguagem. Este começa com a onipotência criadora da linguagem, por assim dizer, incorpora a si o criado, ela o nomeia. Ela é aquilo que cria, e perfaz, ela é palavra e nome. Em Deus o nome é criador por ser palavra, e palavra de Deus é saber por ser nome. "E Deus viu que isso era bom", isto é: ele o conheceu pelo nome. A relação absoluta do nome com o conhecimento só existe em Deus, só nele o nome, porque é intimamente idêntico à palavra criadora, é o puro 
meio do conhecimento. Isso quer dizer: Deus tornou as coisas cognoscíveis ao lhes dar nomes. Mas o homem só nomeia as coisas na medida em que as conhece. (BENJAMIN, 2011, p.61)

Segundo Benjamin, Deus não criou o homem pela palavra, não o nomeou e nem o submeteu a ela, mas o ofereceu a mesma linguagem que utilizou para criar o mundo. Assim,

o homem é aquele que conhece na mesma língua em que Deus cria. Deus criou o homem à sua imagem, criou aquele que conhece à imagem daquele que cria. É por isso que, quando se diz que a essência espiritual do homem é a linguagem, essa frase precisa de uma explicação. Sua essência espiritual é a linguagem, em que ocorreu a criação. A criação começou na palavra, e a essência linguística de Deus é a palavra. Toda linguagem humana é tão só reflexo da palavra no nome (BENJAMIN, 2011, p.62).

Podemos notar que a linguagem comum do homem não é a mesma palavra criadora divina. É nesse sentido que o homem desejoso de retomar a esta linguagem criadora do início dos tempos redimensionará a linguagem comum, transfigurando-a em linguagem poética. O homem se transformará em poeta, semideus e demiurgo.

Giambattista Vico, em 1730, nos seus Princípios de (uma) Ciência Nova, expõe a ideia de que a linguagem poética seria primitiva, e que os homens passaram dela para a racional, sendo ambas intimamente ligadas. Mais do que isso, Vico concebe a linguagem poética como fato natural e, por conseguinte, entende as imagens não como desvios da linguagem (como consideravam os retóricos), ampliando o pensamento de sua época. Para o filósofo italiano, "os homens do mundo nascente (fanciullo) foram, por sua própria natureza, sublimes poetas." (VICO, 1979, p.42). Enquanto o discurso poético moderno se realiza de maneira "artificial" ou diferentemente da linguagem corrente, observa Vico; na idade primitiva do homem (sua infância) a linguagem era exercida de forma distinta. Enquanto a linguagem poética moderna se esforça para exprimir-se de maneira imaginativa, a linguagem primitiva a exprimia naturalmente. Antônio Lázaro nos explica, na introdução aos Princípios de (uma) Ciência Nova, esse procedimento: 
Quando, por exemplo, se pensa nos eventos descritivos pela mitologia como apenas ficções extravagantes, ou quando se inclina a tratar trabalhos de poesia ou pintura como objetos de prazer ou de entretenimento, deve-se tomar cuidado em não projetar essas atitudes nos povos antigos. Houve períodos em que, longe de ser encarada como uma espécie de embelezamento dispensável da existência civilizada, a poesia era, ao contrário, do modo natural da expressão humana. (LÁZARO apud VICO, 1979, p. XXI).

Nessa perspectiva, tanto a poesia quanto a imaginação infantil apresentam vigorosas fantasias, e as crianças criadoras se assemelhariam aos poetas:

os primeiros homens das nações gentílicas, quais infantes (fanciulli) do nascente gênero humano, como os caracterizamos nas Dignidades, criavam, a partir de sua ideia, as coisas, mas num modo infinitamente diverso daquele Deus. Pois Deus, em seu puríssimo entendimento, conhece, e, conhecendo-as, cria as coisas. Já as crianças, em sua robusta ignorância, o fazem por decorrência de uma corpulentíssima fantasia. E o fazem com uma maravilhosa sublimidade, tamanha e tão considerável que perturbava, em excesso, a esses mesmos que, fingindo, as forjavam para si pelo que foram chamados "poetas", que, no grego, é o mesmo que "criadores". (VICO, 1979, p.76).

Partindo dessa lógica, o filósofo italiano considera que os primeiros poetas é que devem ter nomeado as coisas, "a partir das ideias mais particulares e sensíveis. Eis as duas fontes, esta da metonímia e aquela da sinédoque”. (VICO, 1979, p. 90). Assim como a criança, o poeta escreve como se tivesse visto o objeto de sua reflexão pela primeira vez. Para Vico, "as crianças com as ideias e nomes de homens, mulheres e coisas, que pela primeira vez viram, aprendem e chamam, a seguir, todos os homens, mulheres e coisas, que tenham com os primeiros alguma semelhança ou relação”, sendo esta a grande fonte natural dos caracteres poéticos, com os quais naturalmente pensaram os povos primitivos. (VICO, 1979, p.92).

Vico conclui seus argumentos apresentando a ideia de que a idade de ouro da humanidade é o tempo em que, como explica Antônio Lázaro (em nota da introdução à obra 
do filósofo italiano), "se degradaram as grandes metáforas dos poetas teólogos e/ou fundadores e inventores." (LÁZARO apud VICO, 1979, p.149). Para desenvolver sua ideia, Vico dividirá a humanidade em três estágios (o divino, o heroico e o humano), os quais representam, cada um à sua maneira, sua língua e visão do mundo. O estágio inicial (que nos interessa mais de perto aqui) corresponde a uma visão criadora ou "poética". Neste estágio, o homem, por meio da imaginação, antes mesmo de usar sua capacidade racional e refletir sobre as coisas, as criam, considerando-as realidades externas a ele. A criação poética está intrinsecamente ligada à capacidade imaginativa e criadora do homem, - que diminui com o desenvolvimento da razão. Antonio Candido nos esclarece que,

a linguagem poética, eminentemente criadora, nasce da necessidade de exprimir, mas não sucede a uma linguagem não-poética; pelo contrário, precede-a, tanto assim que o verso sempre surge antes da prosa. Com o correr de tempo e o aparecimento da linguagem racional, da explicação racional, etc., a forma anterior perde a sua exclusividade, mas permanece ao lado da outra. O poético se prolonga pelo racional, ou metafísico, adentro (CANDIDO, 2004, p.146147).

Portanto, a importância concedida à imaginação é considerada primordial,

pois

a linguagem figurada nasce de uma inopia; mas não sucede a uma linguagem própria. O que falta é precisamente esta, que só poderá se desenvolver numa fase racional, na qual se estabeleça o conhecimento das coisas pelas causas. Portanto, a linguagem figurada da poesia é a forma primordial que institui a visão do mundo, permanecendo em nosso tempo como sobrevivência. (CANDIDO, 2004, p.147-148).

De acordo com Alfredo Bosi, “toda (a Scienza Nueva) [está] voltada para entender a natureza do trabalho poético, o ser da Poesia, em termos de linguagem, cuja ordem imanente se colhe na unidade de sentidos, memória e fantasia.” (BOSI, 1977, p.210). Desse modo, a poesia imaginativa e o mundo infantil estão intrinsecamente ligados, e a modernidade poética vai refletir, principalmente através da busca da evasão da vida cotidiana, esse 
modo de criação. Para Bosi, "nesses tempos, ingratos para a sensibilidade heroica, o poeta procura reconquistar, 'com arte e indústria' o poder inventivo da linguagem, que lhe é conatural, e tenta evitar a redução do seu discurso a um universo de juízos convencionais.” (BOSI, 1977, p.211).

Esta concepção de poesia como obra do instinto e da imaginação se afirma novamente na segunda metade do século XVIII, como reação ao predomínio do classicismo francês na Europa, sendo divulgado pelo pensamento pré-romântico e romântico, do qual o principal representante foi o Sturm und Drang (1770), de Herder, Goethe e Schlegel entre outros românticos alemães, que

acreditavam que a poesia é obra do instinto e da imaginação livres, que ela é mais espontânea e genuína nos períodos iniciais da civilização, na juventude da humanidade, quando o instinto, a imaginação e a tradição oral eram mais fortes do que a razão e a reflexão, quando a 'poesia era a linguagem natural dos homens'... (AUERBACH, 2007, p.343).

É desse pensamento que provém a ideia de que a poesia do tempo moderno deve retornar à sua fonte primordial, a do "espírito do povo", para se tornar verdadeira. A isso se soma, como salienta Auerbach, o fato de que o objetivo da imaginação primitiva é estabelecer "limites fixos como proteção material e psicológica contra o caos do mundo circundante" (AUERBACH, 2007, p. 352), pensamento que concorda plenamente com o ideal primordial do mito de transformar o caos em cosmos, como já dissemos.

Acompanhando os passos do pensamento de Vico, Alfredo Bosi afirma que a criação poética é fruto da memória na medida em que ela "aparece como faculdade de base" (BOSI, 1977, p.204), e o meio pelo qual se "modela" a imagem é a fantasia. Desta se produz tanto os mitos quanto a prática poética em si, o texto. De acordo com Vico,

entre os Latinos chama-se "memória" a faculdade que guarda as percepções recolhidas pelos sentidos, e "reminiscência" a que as dá à luz. Mas memória significa também a faculdade pela qual nós conformamos as imagens, e que as dá, e que os Gregos chamaram "fantasia", e nós comumente dizemos "imaginar" dizem os Latinos memorare. Será, por acaso, porque não podemos fingir em nós senão o 
que pelos sentidos percebemos? De certo, nenhum pintor pintou jamais qualquer gênero de planta ou de ser animado que não o retirasse da natureza: porque hipogrifos e centauros são verdades da natureza ficticiamente combinadas. (VICO apud BOSI, 1977, p.200)

Aliado a isso, podemos pensar que a memória no texto literário tem o papel de reelaborar o que foi vivido (ou imaginado) pelo poeta de modo que ela possa se realizar no poema. Sem essa reelaboração a memória simplesmente representaria o passado comum a qualquer pessoa.

Essa perspectiva nos leva novamente a relacionar a linguagem poética ao mito, nesse momento, pela expressão da memória representada originalmente pela figura da musa, entidade mitológica que auxilia e/ou inspira o poeta em sua criação. Um ponto a se ressaltar sobre a figura da Musa é o fato de que o canto do poeta provém da memória (Mnemosyne). Segundo Vernant, em Mito e pensamento entre os gregos, a memória (Mnemosyne), mãe das musas, caracterizava-se, no pensamento mítico e arcaico grego, por ter o conhecimento do Tempo: o passado, o presente e o futuro. Mnemosyne tinha, igualmente, o conhecimento do Espaço: do mundo do visível e invisível, do espaço dos vivos e dos mortos. Mnemosyne não era, como a memória, conhecimento de um tempo passado, mas, ao contrário, memória de um tempo que continua no presente e no futuro, pois é memória de um tempo arcaico (archê), primordial, original da formação e organização do mundo e do espaço. A memória mítica e arcaica, portanto, tem, segundo Vernant, a onisciência: ela vê tudo em todos os momentos. Ela está além do começo e do fim. Ela tem sabedoria suprema ao conhecer o passado, o presente e o ausente, o todo do tempo e do espaço e, como que por adição, aquilo que excede esse todo. Possuído pelas musas o poeta é o intérprete de Mnemosyne. (Cf. VERNANT, 1990, p. 105-131).

A memória também está associada aos atos ligados à criação: inventar, medir, refletir, cuidar. É através da memória que a unidade é revelada. Nela, presente, passado e futuro se fundem. No momento em que o poeta é possuído pelas Musas, ele absorve o conhecimento de Mnemosyne e obtém todo conhecimento expresso pelas genealogias, atin- 
gindo o ser em toda a sua profundidade. É a descoberta da origem, do movimento primordial: a gênese dos deuses, o nascimento da humanidade, o surgimento do cosmos. Portanto, é por meio da memória que o poeta tem acesso ao indecifrável e consegue enxergar o invisível. Como aponta Eliade, é "graças a memória primordial que ele é capaz de recuperar, o poeta inspirado pelas Musas tem acesso às realidades originais. Essas realidades manifestam-se nos Tempos míticos do princípio e constituem o fundamente deste Mundo" (ELIADE, 1998, p.108). O canto das Musas revela como o mundo e seus habitantes surgiram. Mircea Eliade ainda ressalta o papel fundamental que a memória (a anamnesis) tem na libertação da obra no tempo:

o essencial é recordar todos os acontecimentos testemunhados no curso da duração temporal. Essa técnica relaciona-se, portanto, à concepção arcaica (...) a importância de se conhecer a origem e a história de uma coisa para podê-la dominá-la. Certamente, percorrer o tempo em direção contrária implica uma experiência que depende da memória pessoal, ao passo que o conhecimento da origem se reduz à apreensão de uma história primordial exemplar, de um mito. Mas as estruturas são homologáveis: trata-se sempre de recordar, detalhada e precisamente, o que separou no princípio e a partir de então. (ELIADE, 1998, p.83, grifos do autor).

$\mathrm{Na}$ antiguidade, era dado à poesia o poder de tornar presentes os fatos passados e futuros, de renovar e restaurar a vida. A palavra cantada "tinha o poder de fazer o mundo e o tempo retornarem à sua matriz original e ressurgirem com o vigor, perfeição e opulência de vida com que vieram à luz pela primeira vez." (TORRANO, 1995, p.20). Esse poder ontofânico do mito pode ser evidenciado hoje na experiência poética, no momento em que a poesia consegue fundar uma realidade própria a ela, quando funda seu próprio mundo.

\section{MYTH AND POETRY, INTERCHANGEABLE SPACES}

ABSTRACT: The literature is closely associated with the mythical dimension because of the strong brands of literary nature (such as the myth) is to promote the encounter of the individual with deep memory (anamnesis) of culture. Literature - and more specifically the poetic language - you want to relive the experience of the first appointment of the things of the world as in the early days. This experience is essentially poetic, which situation inaugural similar fields myth and poetry.

KEYWORDS: Myth; Poetry; Literature. 


\section{REFERÊNCIAS}

AUERBACH, Erich. Ensaios de Literatura Ocidental. Org. de Davi Arrigucci Jr. e Samuel Titan Jr. (Trad. de Samuel Titan Jr. e José M. de Macedo). São Paulo: Duas Cidades; Editora 34, 2007.

BENJAMIM, Walter. Escritos sobre Mito e Linguagem. Org. e apres. J. M. Gagnebin. (Trad. de Susana Kampff e Ernani Chaves). São Paulo: Duas Cidades; Editora 34, 2011.

BOSI, Alfredo. O Ser e o Tempo na Poesia. São Paulo: Cultrix, 1977.

CANDIDO, Antonio. O estudo analítico do poema. São Paulo: Associação Editorial Humanitas, 2004.

CASSIRER, Ernst. Linguagem e mito. (Trad. J. Guinsburg e Míriam Schnaider-man). São Paulo: Perspectiva, 2000.

ELIADE, Mircea. Mito e realidade. (Trad. Pola Civelli) São Paulo: Perspectiva, 1998.

FRYE, Northrop. Código dos códigos: A Bíblia e a literatura. (Trad. de Flávio Aguiar) São Paulo: Boitempo, 2004.

HEIDEGGER, Martin. A origem da obra de arte. (Trad. de Idalina Azevedo e Manuel A. de Castro). São Paulo: Edições 70, 2010.

JABOULLE, Victor. "Mito e literatura: algumas considerações acerca da mitologia clássica na literatura ocidental”. In: Mito e literatura. Mem Martins, Portugal: Inquérito, 1993.

MIELIETINSKI, E. M. A poética do mito. (Trad. Paulo Bezerra) Rio de Janeiro: ForenseUniversitária, 1987.

TORRANO, Jaa. "Estudo". In: HESÍODO. Teogonia: A origem dos deuses. Trad. de Jaa Torrano. São Paulo: Iluminuras, 1995.

VERNANT, J. P. “Aspectos míticos da memória e do tempo”. In: Mito e pensamento entre os gregos: estudos de psicologia histórica. (Trad. Haiganuch Sarian) Rio de Janeiro: Paz e Terra, 1990.

VICO, Giambattista. Princípios de uma ciência nova: acerca da natureza comum das nações. (Trad. Antônio Lázaro) São Paulo: Abril Cultural, 1979.

Recebido em: 02/10/2017. Aprovado em: 26/11/2017. 